Western University Scholarship@Western

Department of Economics Research Reports

Economics Working Papers Archive

1980

\title{
Intrametropolitan Location of Employment
}

Mark W. Frankena

Follow this and additional works at: https://ir.lib.uwo.ca/economicsresrpt

Part of the Economics Commons

Citation of this paper:

Frankena, Mark W.. "Intrametropolitan Location of Employment." Department of Economics Research Reports, 8016. London, ON: Department of Economics, University of Western Ontario (1980). 
ISSN: $\quad 0318-725 \mathrm{X}$

ISBN: $0-7714-0197-3$

RESEAROH REPORT 8016

INTRAMETROPOLITAN LOCATION

OF EMPLOYMENT

'by

Mark W. Frankena

August, 1980 


\begin{abstract}
Differences among employment density functions for members of different income and sex groups in Toronto in 1971 indicate that jobs held by females were more centralized than jobs held by males, jobs held by lower-middle income females were more centralized than jobs held by other females, and jobs held by high income males were more centralized than jobs held by other males. It is also concluded that use of the negative exponential functional form involves a serious misspecification of the employment density function.
\end{abstract}




\title{
Intrametropolitan Iocation of Employment
}

\author{
Mark W. Frankena ${ }^{1}$
}

Department of Economics, University of Western Ontario London, Ontario, Canada N6A 5C2

\section{Introduction}

The primary purpose of this paper is to determine whether the intrametropolitan location of employment is significantly different for members of different income groups and for males and females. This topic has important Implications for the understanding of other aspects of urban spatial structure, e.g., variations in residential location patterns among families with different incomes and with different numbers of male and female workers. It also has important implications for the evaluation of urban policies, e.g., the incidence of transportation policies. In the present study we find that in Toronto in 1971 differences among the employment density functions for members of different income and sex groups were statistically significant. The results are consistent with the hypotheses that (1) when all income levels are combined, jobs held by females are more centralized than jobs held by males; (ii) jobs held by lower-middle income females are more centralized than jobs held by other females; and (iii) jobs held by high income males are more centralized than jobs held by other males. These empirical results are of some interest; for example, they may help to explain why public transit, which has a comparative advantage in moving people to and from the centers of urban areas, accounts for a larger share of work trips, for females than for males. ${ }^{2}$ 
A secondary purpose of this paper is to test the common assumption that employment density functions are negative exponential. Based on the data for Toronto in 1971, we conclude that use of the negative exponential functional form involves a serious misspecification of the density function. While a negative exponential function implies a constant percentage decrease in density per mile as one moves away from the center of a city, in Toronto in 1971 on average the percentage decrease in employment density per mile was significantly greater near the center of the city than near the periphery. However, this conclusion must be qualified because the estimated density functions were not convex throughout the relevant domain.

\section{Previous Studies}

In contrast to the voluminous literature on urban population density functions and the intrametropolitan residential location of different income groups, there have been only a handful of studies on urban employment density functions and the intrametropolitan employment locations of different income and sex groups.

\section{A. Employment Density Functions}

The first study to estimate urban employment density functions was by Mills [11], [12], who used U.S. census data to estimate density functions for each of four categories of employment (manufacturing, wholesaling, retailing, services). Mills assumed that the density functions were negative exponential and was unable to test this assumption because census data provide only two observations for each urban area, one for the entire central city and one for the entire suburban ring. Subsequently, Mills and Ohta [13] estimated similar density functions for both total employment and manufacturing employment in U.S. urban areas. 
The second study of employment density functions was by Fales and Moses [1], who estimated employment density functions for manufacturing in Chicago in 1873. While they concluded that a regression of employment density on the natural $10 g$ of distance from the center of the city provided a better fit than a Iinear regression of density on distance, their primary purpose was to show that variables other than distance to the center of the city (proximity to railway freight yards, the river, and horsecar lines) were significant determinants of employment density.

The third study of employment density functions was by Kemper and Schmenner [8], who estimated employment density functions for each of ten manufacturing industries under the assumption that the functions were negative exponential. While Kemper and Schmenner estimated only the negative exponential form for employment density functions, they did conclude that one of their findings "appears to be a result of the failure of the negative exponential functional form to describe the observed densities" [p. 423]. The apparent specification error involved in use of the negative exponential form, which they portray in their Fig. 1, is supported by the findings of the present study.

The fourth study of employment density functions was by Mills and Ohta [13], who estimated density functions for total employment and manufacturing employment in Japanese urban areas under the assumption that the functions were negative exponential.

The most recent study of employment density functions was by Moomaw [14], whose work is an extension of the work by Fales and Moses. Moomaw used three alternative functional forms (linear, log-Linear, and double log) for density functions for Industrial employment in Tulsa, Oklahoma, and rejected the linear specification because it was the only one in which the distance variable was not statistically significant. Moomaw also concluded that independent variables in addition 
to distance (e.g., access to railways) were significant determinants of employment density.

A11 five of the studies reviewed above use gross employment density, i.e., employment divided by total land area, or its logarithm, as the dependent variable. By contrast, two studies use the labor/land ratio for land actually used for employment as the dependent variable. These two measures are conceptually different; the former is equal to the latter times the fraction of the total land area used for employment.

The labor/land ratio is used by Fallis [2], who estimated six alternative forms for the function relating the labor/land ratio to distance from the center of the city for manufacturing and commerce in Metropolitan Toronto. Fallis concluded that the function was convex, i.e., the labor/land ratio declines at a decreasing absolute rate as distance from the center increases. The labor/land ratio is also used by Moomaw [14] as an alternative to gross density.

B. Employment Locations for Different Income-Sex Groups and for Different Occupations

The only previous study of the intrametropolitan location of employment for different income and/or sex groups was by Johnson [7], who analyzed the pattern of employment in the New York metropolitan area using Social Security Administration data. Although Johnson's analysis is limited to highly aggregative tabular data, his work provides a useful starting point for the present study. Tables 1 and 2 reproduce some of Johnson's 1962 and 1966 data, which suggest (i) that "high income" jobs (annual labor income of $\$ 8000$ or more in current dollars) and "lower middle income" fobs (\$2500-4999) were more centralized than "upper middle income" jobs $(\$ 5000-7999)$ and "low income" jobs (less than $\$ 2500$ ), and (ii) that jobs held by females were more centralized than jobs held by males. 
TABLE 1

Employment by Individual Labor

Income, New York Metropolitan Area

(Percent of Employment)

\begin{tabular}{|c|c|c|c|c|}
\hline \multirow[b]{2}{*}{ Annual Income } & \multicolumn{2}{|c|}{1962} & \multicolumn{2}{|c|}{1966} \\
\hline & $\begin{array}{c}\text { Central } \\
\text { City }\end{array}$ & Suburbs & $\begin{array}{c}\text { Central } \\
\text { City }\end{array}$ & Suburbs \\
\hline Less than $\$ 2500$ & 34.3 & 34.3 & 30.9 & 34.1 \\
\hline$\$ 2500-4999$ & 31.3 & 28.3 & 25.7 & 24.1 \\
\hline$\$ 5000-7999$ & 20.5 & 23.9 & 22.6 & 23.1 \\
\hline$\$ 8000$ or more & 13.7 & 13.6 & 20.5 & 18.7 \\
\hline TOTAL & 100.0 & 100.0 & 100.0 & 100.0 \\
\hline
\end{tabular}

Note: Incomes are measured in current dollars.

Source: [7], Table 2 . 
TABLE 2

Employment by Sex, New York Metropolitan Area

(Percent of Employment)

\begin{tabular}{|c|c|c|c|c|}
\hline \multirow[b]{2}{*}{ Sex } & \multicolumn{2}{|c|}{1962} & \multicolumn{2}{|c|}{1966} \\
\hline & $\begin{array}{c}\text { Central } \\
\text { City }\end{array}$ & Suburbs & $\begin{array}{c}\text { Central } \\
\text { City }\end{array}$ & Suburbs \\
\hline Female & 39.7 & 37.3 & 40.8 & 39.3 \\
\hline Male & 60.3 & 62.7 & 59.2 & 60.7 \\
\hline TOTAL & 100.0 & 100.0 & 100.0 & 100.0 \\
\hline
\end{tabular}

Source: [7], Table 5. 
A final study which must be reviewed here examines the intrametropolitan location of employment for eight different occupation groups (see Table 3) in the Toronto Census Metropolitan Area in 1971. Gera and Kuhn [6] computed the value of the following quotient for each of the eight occupation groups in each of 63 work zones :

$$
\frac{E_{i j} / \sum E_{i j}}{\sum_{i j /} \sum_{j i} E_{i j}}
$$

where $E_{i j}$ is employment in occupation group $i(i=1,2, \ldots, 8)$ in work zone $j$ $(j=1,2, \ldots, 63)$. For each occupation group they then used the 63 observations to run a linear regression of the quotient in Eq. (1) on the distance of the work zone from the center of the city. The signs and significance levels of the estimated coefficients of the distance variable are shown in Table 3 . The results broadly support the hypothesis that "white-collar jobs are more centrally located than blue-collar jobs" [p. 273]. While Gera and Kuhn do not study employment location differences for males and females, they do present information on the percentage of workers in each occupation group that was female (see Table 3 ). Since females accounted for 37.9 percent of all jobs it follows that females held a disproportionately high share of clericalsales-service white collar jobs and a disproportionately low share of all bluecollar jobs. In light of the finding that white-collar jobs were more centralized than blue-collar jobs and that females accounted for a disproportionate share of white-collar jobs in Toronto, it is not surprising that the present study and the study by Johnson found that jobs held by females were more centralized than jobs held by males in Toronto and New York respectively. The study by Gera and Kuhn complements the present study because the two studies used substantially different tabulations of data constructed from the same underlying data set. ${ }^{3}$ 
TABLE 3

Occupation Groups in Toronto, 1971

Occupation

Coefficient on

Percent Distance

Female

\section{White Collar}

Professionals and high-level management

Semi-professionals, technicians, and middle management

Skilled clerical-sales-services

Semi- and unskilled clerical-sales-services

$\begin{array}{ll}- & 26.7 \\ -* & 39.7 \\ -* * & 69.3 \\ -* * * & 63.7\end{array}$

Blue Collar

Skilled crafts and trades

Semi-skilled manual

Unskilled manual

$+$

$+*$

$+$

7.5

30.0

25.6

Mixed White and Blue Collar

Supervisors and foremen

17.4

Notes:

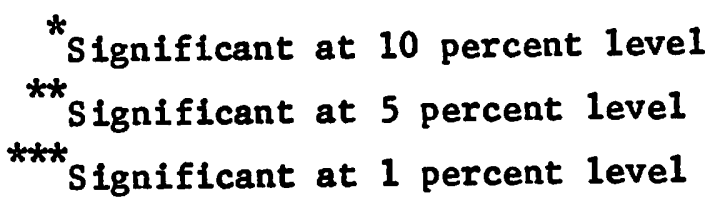

Source: [6], Table 1 , and [5], P. 5 . 


\section{Data for the Present Study}

Previous research on employment density functions has been hampered by limitations on the availability of data, particularly disclosure rules which have generally prevented the U.S. Bureau of the Census from releasing urban employment data for areas smaller than the entire central city and the entire suburban ring. In the 1971 Census of Canada, however, households were asked to specify the address of their place of work, and these addresses were subsequently coded by census tract. The present study is based on a special unpublished tabulation of these data prepared by Statistics Canada for this study. The employment data are broken down by sex and 1970 annual individual employment income for 299 mutually exclusive and exhaustive work zones in the Toronto Census Metropolitan Area (excluding the Toronto islands). The availability of these data has made it possible for the first time to estimate employment density functions for different income and sex groups. Before considering these density functions, it is useful to examine two tables constructed from the data. Table 4 presents data on the percentage distributions of total, female, and male employment among six annual income groups for each of six rings around the center of Toronto (the intersection of King and Yonge Streets). One of the peculiarities of the data is that an individual's workplace refers to his place of employment on the day of the census (June 1, 1971) while an individual's income refers to his 1970 annual labor income. Consequently, people who were employed in 1971 but not in 1970 appear as having zero income in Table $4 .^{4}$

The data in Table 4 suggest that employment for high income $(\$ 10,000$ and over) and low income (\$3000-\$4999) males was more centralized than employment for middle income ( $\$ 5000-\$ 9999)$ males, and that employment for lower-middle income ( $\$ 5000-\$ 6999)$ females was more centralized than employment for other females. 
TABLE 4

Eaployment by Income, Toronto Metropolitan Area, 1971

(Percent of loyment)

(B) Female Employment

\begin{tabular}{lrrrrrr}
\multicolumn{1}{c}{$\$ 0$} & 2.5 & 3.6 & 4.8 & 3.9 & 4.7 & 5.4 \\
Less than $\$ 3000$ & 25.8 & 27.3 & 29.8 & 31.9 & 34.3 & 36.0 \\
$\$ 3000-4999$ & 35.3 & 30.0 & 29.8 & 32.8 & 30.2 & 28.8 \\
$\$ 5000-6999$ & 24.9 & 25.5 & 23.2 & 21.0 & 19.1 & 19.7 \\
$\$ 7000-9999$ & 9.3 & 9.7 & 8.9 & 7.7 & 8.2 & 8.0 \\
$\$ 10000$ and over & $\frac{2.2}{100.0}$ & $\frac{4.0}{100.0}$ & $\frac{3.3}{100.0}$ & $\frac{2.9}{100.0}$ & $\frac{3.4}{100.0}$ & $\frac{2.4}{100.0}$ \\
$\quad$ TotaI & 100 & & & & &
\end{tabular}

(C) Male Employment

\begin{tabular}{|c|c|c|c|c|c|c|}
\hline$\$ 0$ & 1.1 & 1.6 & 1.5 & 1.4 & 1.6 & 1.5 \\
\hline Les8 than $\$ 3000$ & 9.6 & 12.2 & 11.7 & 10.8 & 12.5 & 11.0 \\
\hline$\$ 3000-4999$ & 10.5 & 12.1 & 11.1 & 9.8 & 9.2 & 8.5 \\
\hline 5000-6999 & 17.5 & 18.1 & 19.2 & 20.3 & 20.6 & 19.4 \\
\hline 7000-9999 & 25.6 & 24.1 & 31.0 & 31.9 & 30.3 & 34.0 \\
\hline$\$ 10000$ and over & 35.9 & 32.0 & 25.4 & 25.8 & 25.7 & 25.8 \\
\hline Total & 100.0 & 100.0 & 100.0 & 100.0 & 100.0 & 100.0 \\
\hline
\end{tabular}


Table 5 presents data on the percentages of jobs in each of the same six rings which were held by females and by males. The data indicate that jobs for females were more centralized than jobs for males.

4. Form of the Density Functions

The first task of the present research was to select an appropriate specification for the employment density functions. Most previous studies have used the negative exponential form without comparing it to alternatives. We compared the negative exponential function (2) with alternatives involving additional powers of distance as independent variables. Since we will discuss below the alternative with two powers of distance and ultimately selected the alternative with six powers of distance, these are presented as (3) and (4) respectively:

$$
\begin{aligned}
& \text { In } Y_{i j}=\alpha_{0}+\alpha_{1} X_{j}+\epsilon_{1 i j} \\
& \text { ln } Y_{i j}=\beta_{0}+\beta_{1} X_{j}+\beta_{2} x_{j}^{2}+\epsilon_{2 i j} \\
& \ln Y_{i j}=\gamma_{0}+\gamma_{1} X_{j}+\gamma_{2} X_{j}^{2}+\gamma_{3} X_{j}^{3}+\gamma_{4} X_{j}^{4}+\gamma_{5} X_{j}^{5}+\gamma_{6} X_{j}^{6}+\epsilon_{3 i j}
\end{aligned}
$$

where $Y_{i j}$ is a measure of the density of employment for the $i^{\text {th }}$ income-sex group in the $j^{\text {th }}$ district, $x_{j}$ is the distance in miles from the center of the $j^{\text {th }}$ district to the center of the city, $\epsilon_{\mathrm{Kij}}$ is a stochastic error which has zero mean and constant variance, and $1 n$ is the natural logarithm operator. The "districts" are assumed to be of equal size.

Unfortunately, the "work zones" for which data were available for the present study are not of equal size and hence do not correspond to the "districts" described above. More important, for reasons which are spelled out in detail in an earlier paper [3], there is reason to believe that the error terms for the work zone observations do not have zero means. This is because of the 


\section{TABLE 5}

Bmployment by Sex, Toronto Metropolitan Axea, 1971

$$
\text { (Percent of Employment) }
$$

Miles from the Center

\begin{tabular}{lcccccc}
\cline { 3 - 6 } Sex & $\underline{0-1}$ & $\underline{1-2}$ & $\underline{2-4}$ & $\underline{4-7}$ & $\underline{7-10}$ & $\underline{10 \text { and over }}$ \\
Female & 44.2 & 44.3 & 37.8 & 37.8 & 36.2 & 30.8 \\
Male & $\underline{55.8}$ & $\underline{5.7}$ & $\underline{62.2}$ & $\underline{62.2}$ & $\underline{63.8}$ & $\underline{69.2}$ \\
Total & 100.0 & 100.0 & 100.0 & 100.0 & 100.0 & 100.0
\end{tabular}

Source: Same as Table 4. 
rules of census tract mapping and Statistics Canada rules concerning confidentiality. The latter required us to combine up to six census tracts in defining work zones in areas of Toronto with low employment density while we were able to use individual census tracts as work zones in areas of high employment density. The result of these rules is that districts of low employment density are generally underrepresented in the work zone sample. To compensate for this sampling bias, in the estimation each work zone observation was weighted by its area. This was accomplished by redefining the variables in Eqs. (2) to (4) in terms of work zones rather than districts and multiplying through each equation by the square root of the area of the $j^{\text {th }}$ work zone, i.e., by $A_{j}^{1 / 2}$.

Because our purpose in this study is to compare the locations of jobs for groups of different sizes, the density variable is defined in an unconventional way:

$$
Y_{i j} \equiv \frac{100,000}{\sum_{j} E_{i j}} \cdot \frac{E_{i j}}{A_{j}}
$$

where $E_{1 j}$ is the number of jobs in income-sex group $i$ located in work zone $j$, and $A_{j}$ is the area of work zone $j$ in square miles. $Y_{1 j}$ thus gives the density of jobs for group $i$ in work zone $j$ which would exist if (a) the total number of jobs in group $i$ was inflated or deflated to 100,000 for the metropolitan area as a whole, and (b) these 100,000 jobs had the same percentage allocation among work zones as the actual jobs for the group. With this definition of $Y_{i j}$, the estimated density functions for groups of different sizes will be comparable in the sense that the integral of the expected value of $Y_{i j}$ evaluated over the metropolitan area as a whole will be (approximately) 100,000. As a result, we will be able to compare the locations of jobs for different income-sex groups by comparing the expected values of $Y_{i j}$ at different values of $X_{j}$. 
The least squares estimates of (2) to (4) for total employment in all income-sex groups combined $(i=\mathrm{T} 6)$ are presented in Table 6 . In order to compare the three specifications and some obvious alternatives, we tested the null hypotheses $\beta_{2}=0, \gamma_{2}=\gamma_{3}=, \ldots,=\gamma_{6}=0, \gamma_{3}=\gamma_{4}=\gamma_{5}=\gamma_{6}=0$, and $\gamma_{1}=0$ $(1=2, \ldots, 6)$. Each of the null hypotheses was rejected at the 1 percent significance level using the appropriate $F$ and t-statistics. Eqs. (3) and (4) account for 2.0 and 7.5 percent respectively of the variation in the dependent variable which is left unexplained by (2).

The differences between the estimates of (2), (3) and (4) are clearest if one compares the expected values of $\ln Y_{i}$ given $X, E\left(\ln Y_{i} \mid X\right)$, and the first differences in $E\left(\ln Y_{i} \mid X\right)$ as $X$ increases (see Table 7). Whereas for Eq. (2) $E\left(\ln Y_{i} \mid X\right)$ is a linear function of $X$, for equation (3) $E\left(\ln Y_{i} \mid X\right)$ is a strictly convex function of $X$. Thus, while the negative exponential function (2) Implies a constant percentage decrease in employment density per mile as one moves away from the center of the city, the estimate of the more flexible functional form (3) indicates that in fact in Toronto in 1971 the percentage decrease in employment density per mile was significantly greater near the center of the city than near the periphery.

Unfortunately for those who like neat results, the estimates for Eq. (4) are less clear-cut. While $E\left(\ln Y_{1} \mid X\right)$ is still a decreasing monotonic function of $\mathrm{X}$, it is no longer a convex function of $\mathrm{X}$ throughout the relevant domain $(0 \leq \mathrm{X} \leq 25)$. For some unknown reason there is a "bump" in the density function between 4 and 8 miles from the city center. Nevertheless, it remains true that the percentage decrease in employment density per mile was greater near the center of the city than near the periphery.

Based on these findings, one of the conclusions of this study is that the negative exponential functional form (2) involves a serious misspecification 
TABLE 6

Estimates of Eqs. (2) to (4) for Total Employment in Al1 Income-Sex Groups Combined $(1=\mathrm{T} 6)^{a}$

\begin{tabular}{|c|c|c|c|}
\hline & (2) & (3) & (4) \\
\hline$\alpha_{0}, \beta_{0}, \gamma_{0}$ & $\begin{array}{l}6.68117 \\
(41.7)\end{array}$ & $\begin{array}{l}7.82945 \\
(24.2)\end{array}$ & $\begin{array}{l}10.0310 \\
(7.6)\end{array}$ \\
\hline$\alpha_{1}, \beta_{1}, \gamma_{1}$ & $\begin{array}{l}-.250149 \\
(-30.1)\end{array}$ & $\begin{array}{l}-. .427487 \\
(-9.6)\end{array}$ & $\begin{array}{l}-3.23126 \\
(-3.1)\end{array}$ \\
\hline$\beta_{2}, \gamma_{2}$ & - & $\begin{array}{l}.562881 \times 10^{-2} \\
(4.1)\end{array}$ & $\begin{array}{l}.881092 \\
(3.0)\end{array}$ \\
\hline$\gamma_{3}$ & - & - & $\begin{array}{l}-.113394 \\
(-3.0)\end{array}$ \\
\hline$\gamma_{4}$ & - & - & $\begin{array}{l}.711549 \times 10^{-2} \\
(2.9)\end{array}$ \\
\hline$\gamma_{5}$ & - & - & $\begin{array}{l}-.215427 \times 10^{-3} \\
(-2.8)\end{array}$ \\
\hline$\gamma_{6}$ & - & - & $\begin{array}{l}\left(2.252730 \times 10^{-5}\right. \\
(2.7)\end{array}$ \\
\hline SE & 1.918 & 1.902 & 1.860 \\
\hline $\mathrm{N}$ & 299 & 299 & 299 \\
\hline
\end{tabular}

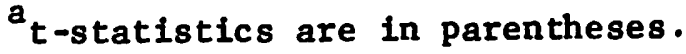




\section{TABLE 7}

Estimates of $E\left(\ln Y_{1} \mid X\right)$ from Eqs. (2) to (4) for Total Employment in All Income-Sex Groups Combined ( $i=T 6)$

Eg. (2)

\begin{tabular}{|c|c|c|}
\hline \multirow[b]{2}{*}{$\underline{x}$} & & \multirow[b]{2}{*}{$\begin{array}{c}\text { First } \\
\text { Difference }\end{array}$} \\
\hline & $E\left(\ln Y_{1} \mid X\right)$ & \\
\hline 0 & 6.68 & \\
\hline 1 & 6.43 & -.25 \\
\hline 2 & 6.18 & -.25 \\
\hline 3 & 5.93 & -.25 \\
\hline 4 & 5.68 & -.25 \\
\hline 5 & 5.43 & -.25 \\
\hline 6 & 5.18 & -.25 \\
\hline 7 & 4.93 & -.25 \\
\hline 8 & 4.68 & -.25 \\
\hline 9 & 4.43 & -.25 \\
\hline 10 & 4.18 & -.25 \\
\hline 11 & 3.93 &.- .25 \\
\hline 12 & 3.68 & -.25 \\
\hline 13 & 3.43 & -.25 \\
\hline 14 & 3.18 & -.25 \\
\hline 15 & 2.93 & -.25 \\
\hline 16 & 2.68 & -.25 \\
\hline 17 & 2.43 & -.25 \\
\hline 18 & 2.18 &.- .25 \\
\hline 19 & 1.93 & -.25 \\
\hline 20 & 1.68 & -.25 \\
\hline 21 & 1.43 & -.25 \\
\hline 22 & 1.18 & -.25 \\
\hline 23 & .93 & -.25 \\
\hline 24 & .68 & -.25 \\
\hline
\end{tabular}

Eq. (3)

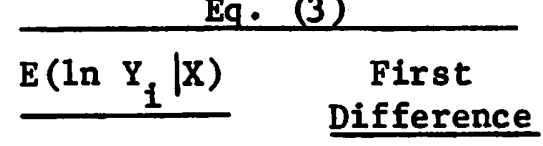

7.83

7.41

7.00

6.60

6.21

5.83

5.47

5.11

4.77

4.44

4.12

3.81

3.51

3.22

2.95

2.68

2.43

2.19

1.96

1.74

1.53

1.33

1.14

.97

.81

$-.42$

$-.41$
Eg. (4)

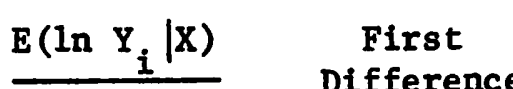

10.03

7.57

6.29

5.73

5.56

5.54

5.53

5.45

5.26

4.96

4.57

4.13

3.68

3.24

2.85

2.52

2.26

2.05

1.88

1.72

1.55

1.35

1.13

0.92

0.79
Difference :

$-2.46$

$-1.28$

$-.56$

$-.17$

$-.02$

$-.01$

$-.08$

$-.19$

$-.30$

-.39

$-.44$

$-.45$

$-.44$

-.39

-.33

- .26

- .21

$-.17$

-.16

$-.17$

- .20

- .22

- .21

$-.13$ 
of the density function. It is clear, moreover, that the specification error involved in the negative exponential functional form is not unique to Toronto. Some of the deficiencies which Kemper and Schmenner [8] attribute to employment density functions in general almost certainly stem from their choice of the negative exponential specification. With this specification, it is easy to understand their conclusion that "the density gradient estimates were surprisingly sensitive to several things including: (i) the density of the analysis zones in the immediate vicinity of the city center, (ii) the location of the city center itself, (iii) the degree of aggregation of the data, and (iv) the estimation technique itself" [p. 425]•

5. Density Functions for Different Income-Sex Groups

In this section, we discuss estimation and hypothesis tests for density functions for different income-sex groups. Based on the results of the preceding section, we used the specification in Eq. (4) for all the work discussed here. 6

First, we broke the data down for sex (but not income) and estimated density functions for male employment $(1=M 6)$ and female employment (F6).

Second, we broke the data down by income (but not sex). For male and female employment combined, we estimated density functions for five income groups: $i=T 1$ (employed in 1970 with income of less than $\$ 3,000$ ), T2 $(\$ 3,000-4,999), \mathrm{T} 3(\$ 5,000-6,999), \mathrm{T} 4(\$ 7,000-9,999)$, and T5 $(\$ 10,000$ and over). ${ }^{7}$

Third, we broke the data down by sex and income. We estimated density functions for the same five income groups for males alone (MI to M5) and for females alone (F1 to F5). 8 
Finally, corresponding to each of the last 15 groups (T1 to T5, M1 to M5, F1 to F5) we also estimated a density function for members of the same "sex" group who were not in the same income group. For example, corresponding to $T 1$ we estimated a density function for the "complement" of $T 1$, 1.e., for $\tilde{\mathrm{T}} 1 \equiv \mathrm{T} 2+\mathrm{T} 3+\mathrm{T} 4+\mathrm{T} 5$, and corresponding to $\mathrm{T} 2$ we estimated a density function for $\tilde{\mathrm{T}} 2 \equiv \mathrm{T} 1+\mathrm{T} 3+\mathrm{T} 4+\mathrm{T} 5$, etc.

Taking the income-sex groups two at a time in the obvious combinations (e.g., M5 and F5, M5 and $\tilde{M} 5, M 5$ and M4, etc.), we performed the standard Chow test for the nul1 hypothesis of equality of two regression equations [9, p. 373] For most such pairs the equations were significantly different at the 5 or 1 percent levels. The only exceptions were some adjacent income groups for the same sex, e.g., M3 and M4.

Thus, we conclude that in Toronto in 1971 there were statistically significant differences in employment density functions for different income and/or sex groups as long as sex is different and/or income levels are substantially different for the groups being compared. 9

\section{Comparison of Job Locations for Different Income-Sex Groups}

The purpose of this section is to determine whether any simple summary statements can be made on the basis of the density functions discussed above about how employment locations of different income and/or sex groups differ. To be useful as "stylized facts" in the urban literature, such summary statements should pertain to $E\left(Y_{i} \mid X\right)$, the expected value of $Y_{i}$ (our relative density measure), rather than to $E\left(\ln Y_{i} \mid X\right)$, the expected value of $\ln Y_{i}$. If the stochastic error $\epsilon_{3 i j}$ in Eq. (4) were normally distributed with mean zero and constant variance $\sigma_{i}^{2}$ for districts, then $E\left(Y_{i} \mid X\right)$ could be computed as follows $[10, p \cdot 33]:{ }^{10}$ 


$$
E\left(Y_{i} \mid X\right)=e^{\sigma_{1}^{2} / 2} e^{E\left(\ln Y_{i} \mid X\right)}
$$

In light of (5), $E\left(Y_{1} \mid X\right)$ should have the property that its integral evaluated over the area of the city is approximately 100,000. In fact, when we computed $E\left(Y_{1} \mid X\right)$ according to $(6)$, we found that for the various income-sex groups the integrals in question were only about $75,000-80,000$. This result could occur if $\epsilon_{3 i j}$ was not normally distributed, since in that case (6) could give a seriously biased estimate of $E\left(Y_{i} \mid X\right)$. As a result, we derived an estimate of $E\left(Y_{i} \mid X\right)$ by using our knowledge of the value of its integral over the area of the city rather than relying on the assumption that $\epsilon_{3 i j}$ is normally distributed. We computed $\mathrm{E}\left(\mathrm{Y}_{1} \mid \mathrm{X}\right)$ as follows:

$$
E\left(Y_{1} \mid X\right)=B_{i} e^{E\left(\ln Y_{1} \mid X\right)}
$$

where $B_{1}$, a constant which takes the place of $e^{\sigma_{1}^{2} / 2}$ in $(6)$, is determined as the solution of the following equation:

$$
B_{i} \int_{0}^{25} \pi X e^{E\left(\ln Y_{i} \mid X\right)} d X=99,000
$$

Use of (8) is justified by the assumptions that the Toronto Census Metropolitan Area is a semicircle and that 99 percent of the jobs in each income-sex group are located within 25 miles of the city center. The bias introduced into the estimation of $E\left(Y_{i} \mid X\right)$ by these assumptions is evidently small compared to the bias that would be introduced by assuming that $\epsilon_{3 i j}$ is normally distributed. Having determined $E\left(Y_{i} \mid X\right)$ for each income-sex group, we were interested in using the results to determine which groups had the more centralized job distributions. There are two ways that one might determine which groups had the more centralized jobs:

a. Comparison of $E\left(Y_{i} \mid X\right)$ :

Suppose that for any two income and/or sex groups $(i=m, n)$, one graphed the expected values of $Y_{i}$ against $X$, and that the graphs intersected exactly 
once, with $E\left(Y_{m} \mid X\right)>E\left(Y_{n} \mid X\right)$ for $0 \leq X<X^{*}$ and $E\left(Y_{m} \mid X\right)<E\left(Y_{n} \mid X\right)$ for $X>X^{*}$.

In this case one could conclude unambiguously that jobs for the $\mathrm{m}^{\text {th }}$ group were more centralized than jobs for the $\mathrm{n}^{\text {th }}$ group. Unfortunately, when we compared $E\left(Y_{1} \mid X\right)$ for most of the relevant pairs of income and/or sex groups, the graphs intersected three or more times, so we are unable to make such simple statements about differences in employment patterns. For example, Table 8 shows the values of $E\left(Y_{i} \mid X\right)$ for all jobs held by females (F6) and all jobs held by males (M6). It can be seen that the expected value of relative employment density is greater for females for $0 \leq \mathrm{X} \leq 1$ and $4 \leq \mathrm{X} \leq 8$ but that it is greater for males for $2 \leq x \leq 3$ and $9 \leq x \leq 24$.

b. Comparison of Integrals of $E\left(Y_{i} \mid X\right)$

Fortunately, there is an alternative way of comparing the spatial distributions of jobs for two different income-sex groups which gives clearer results for Toronto in 1971. Suppose that one computes the expected number of jobs held by members of two income-sex groups $(i=m, n)$ which are located within $X^{*}$ miles of the center of a semi-circular city:

$$
J_{I}\left(X^{*}\right)=\int_{0}^{X *} \pi X E\left(Y_{1} \mid X\right) d X
$$

If $J_{m}\left(X^{*}\right)>J_{n}\left(X^{*}\right)$ for $0 \leq X^{*}<25$, then one can conclude that fobs for group $m$ are more centralized than jobs for group $n .^{11}$

Table 9 presents the values of $J_{i}\left(X^{*}\right)$ for 12 of the income-sex groups considered in this study for various values of $X^{*}$ between .5 and 20 . Examination of this table reveals the following simple patterns in the location of emp loyment :

(i) Combining all income levels, jobs held by females (F6) were more centralized than jobs held by males (M6). For example, one would expect about 15 percent of jobs held by females and 12 


\section{TABLE 8}

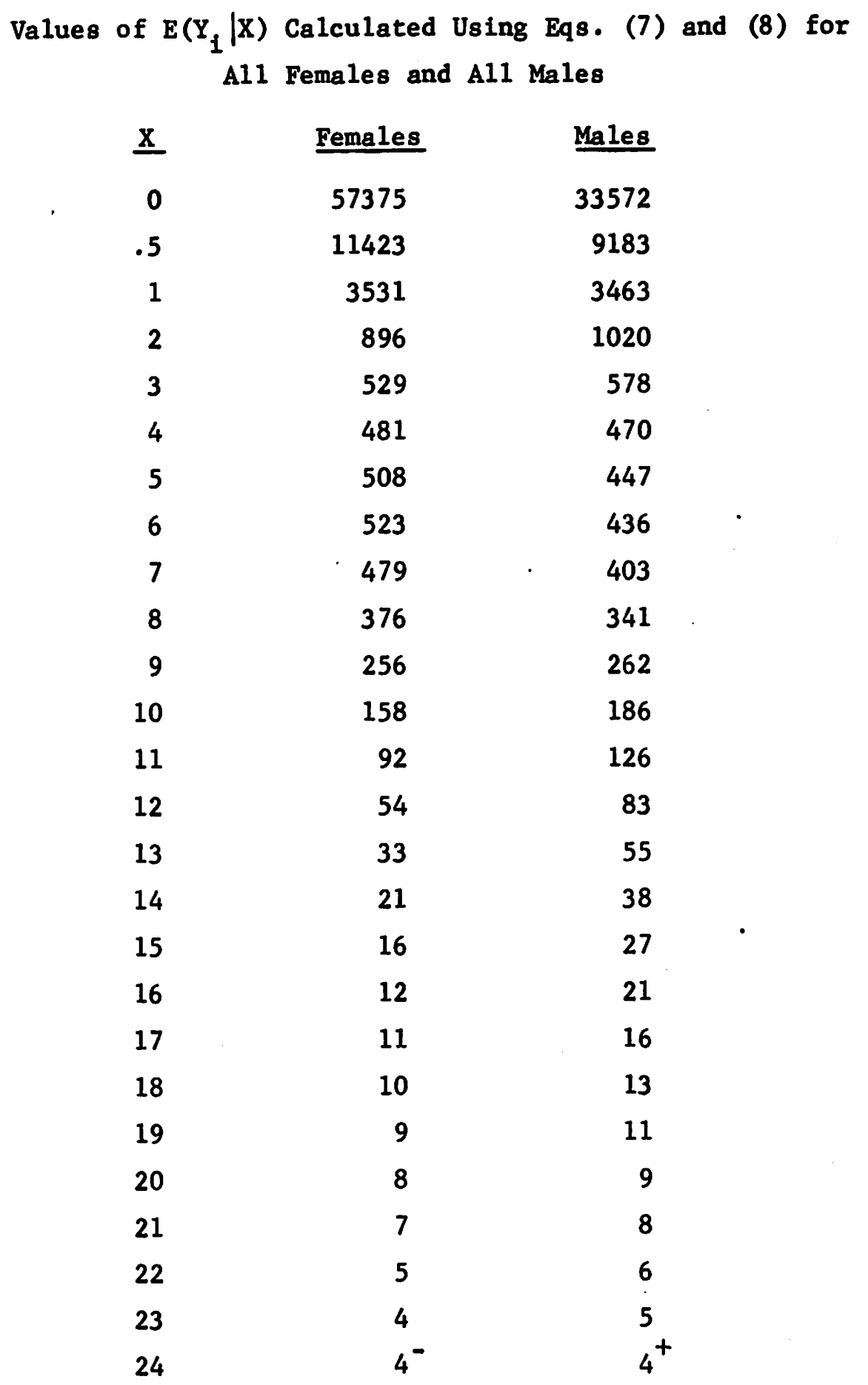


啨

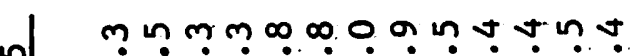

n

官

里

*্.

$m$

o $0.0 m$ n. ஸึ่

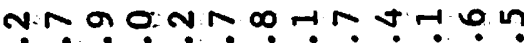

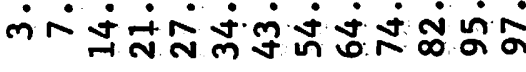

2 $\infty$ ก.

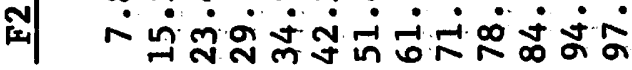

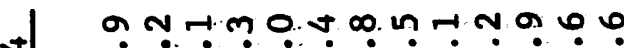

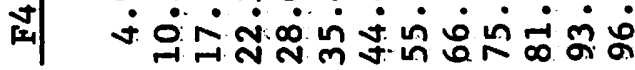

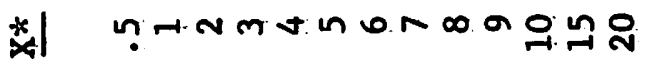

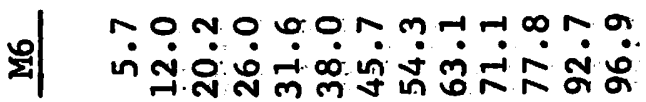

เอ

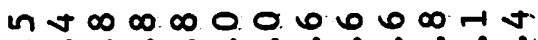

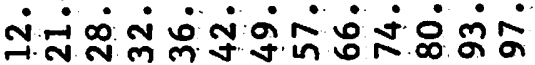

或

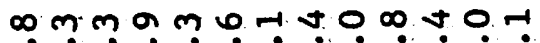

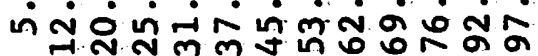

이 이

m mก

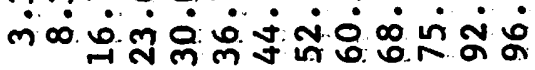

ข้

0, 00 on

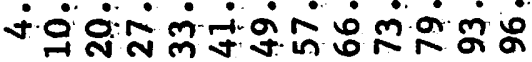

妾

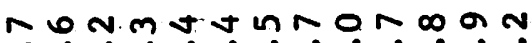

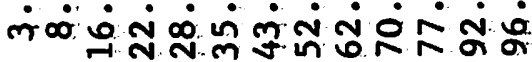

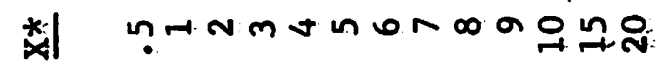


percent of jobs held by males to be within one mile of the center of Toronto in 1971. Similarly, one would expect about 84 percent of jobs held by females and 78 percent of jobs held by males to be within 10 miles of the center.

(ii) Among jobs held by females, lower middle income jobs (F3) were by far the most centralized. For example, one would expect 26 percent of lower middle income jobs held by females to be within one mile of the center. By comparison, using information not presented in the table, one would expect only 13 percent of other jobs held by females $(\tilde{\mathrm{F}} 3=\mathrm{F} 1+\mathrm{F} 2+\mathrm{F} 4+\mathrm{F} 5)$ to be within one miles of the center.

(iii) Among jobs held by males, high income jobs (M5) were by far the most centralized, particularly for $X^{\star}<5$. For example, one would expect 21 percent of high income jobs held by males to be within one mile of the center. By comparison, using information not presented in the table, one would expect only 10 percent of other jobs held by males $(\tilde{M} 5=M 1+M 2+M 3+M 4)$ to be within one mile of the center.

(iv) Inspection of Table 9 confirms the results of the Chow tests reported in Section 5 above, namely, at any income level jobs held by females have a significantly different spatial distribution than jobs held by males. For example, lower middle income jobs held by females (F3) are much more centralized than lower middle income jobs held by males (M3). Also, high income jobs held by females (F5) are relatively concentrated between 3 and 9 miles from the center while high income jobs held by males are more concentrated close to the center and farther out in the suburbs. 


\section{Summary and Implications}

The basic empirical conclusions of this study are:

(a) The negative exponential functional form involves a serious misspecification of the employment density function for Toronto in 1971. While a negative exponential function implies a constant percentage decrease in density per mile as one moves away from the center, in Toronto the percentage rate of decrease in density per mile as one moves away from the center was highly variable. On average, the percentage decrease in employment density per mile was significantly greater near the center of the city than near the periphery.

(b) There were statistically significant differences among the employment density functions for members of different income and/or sex groups in Toronto in 1971. The results are consistent with the hypotheses that (i) when all income levels are combined, jobs held by females are more centralized than jobs held by males; (ii) jobs held by lower-middle income females are more centralized than jobs held by other females; and (iii) jobs held by high income males are more centralized than jobs for other males.

These results suggest some important "stylized facts" about the intraurban location of employment, in total and broken down by sex and income. Moreover, the results for Toronto are generally consistent with the less detailed results reported for New York by Johnson. However, further empirical studies are needed before these results can be generalized, because the central business districts of both Toronto and New York are national centers for office-type employment. For example, in the case of Toronto, the heavy concentrations of high income jobs held by males and lower-middle income jobs held by females are presumably complementary and both related to the large volume of office-type employment (corporate headquarters, financial services, 
provincial and municipal governments, university, hospital) and retail employment near the center.

A large portion of the Aiterature on the income distributional effects of government policies in urban areas relies on inferences based on the stylized facts about residential location patterns of different income groups. The results of this study should increase our understanding of distributional effects, particularly in the case of transportation projects. For example, using these stylized facts, it does not take a great deal of ingenuity to figure out that high income males are likely to receive the largest net benefit from the massive provincial subsidies for the GO Transit commuter railway which connects outlying suburbs with the central business district in Toronto. 


\section{Footnotes}

${ }^{1}$ I am grateful to Kathleen Day for research assistance.

${ }^{2}$ A survey in four Canadian urban areas found that the share of work trips by transit was 44 percent for females compared to 18 percent for males. See $[4, \mathrm{p} .7]$.

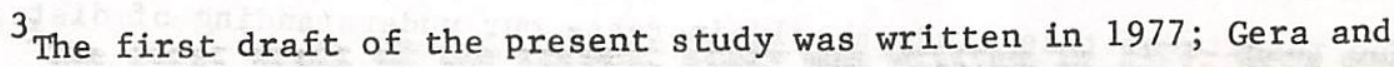
Kuhn carried out their work independently in 1978.

${ }^{4}$ In cases where workers changed employment locations between Jan. 1, 1970 and June 1, 1971, there will be measurement errors in the data.

${ }^{5}$ For convenience in the remainder of the paper we treat urban space as continuous rather than as being divided into discrete districts or work zones, and hence we drop the subscript $j$.

6 To save space, the estimates of these density functions are not reproduced here.

7 Data used to estimate density functions for $T 6, \mathrm{M} 6$, and F6 include data for people who were employed in 1971 but not in 1970 and who consequently had reported incomes of zero in Table 4. However, data for this group were not used to estimate any of the density functions based on data broken down by income.

${ }^{8}$ Since the logarithm of zero is undefined, whenever the employment level for group $i$ in work zone $j$ was measured as zero, this employment level was assigned an arbitrarily small value of one. Of the 299 work zones, there were 3 zeros for M2, one for F3, 19 for F4, and 64 for F5. The large share 
of zeros for F4 and F5 could be interpreted as evidence that the assumption that $\epsilon_{3 i j}$ 'in Eq. (4) is normally distributed for districts is inappropriate. ${ }^{9}$ It should be noted that the tests of statistical significance are based on the assumption that $\epsilon_{31 j}$ is normally distributed for districts. The assumption of normality is questioned in footnote 8 and in Section 6 below.

10 Because the observations were weighted by area in square miles in the estimation, the appropriate estimator for $\sigma_{1}^{2}$ would be the square of the standard error of the regression times the ratio of the number of observations (299) to the total area of the observations in square miles (1399).

${ }^{11}$ From Eqs. (7) and (8), $J_{i}(25) \equiv 99000$ for all $i$ 


\section{REFERENCES}

1. R. L. Fales and L. N. Moses, Land-use theory and the spatial structure of the nineteenth-century city, Regional Sci. Assoc. Papers 28, $49-80$ (1972)

2. G. Fallis, Factor substitution, employment density and suburbanization, J. Urban Econ. 6, 156-175 (1979).

3. M. W. Frankena, A bias in estimating urban population density functions, J. Urban Econ. 5, 35-45 (1978).

4. M. W. Frankena, "Urban Transportation Economics," Butterworths, Toronto (1979).

5. S. Gera and P. Kuhn, "Occupation, Locational Patterns and the Journeyto-Work," (Ottawa: Economic Council of Canada, Discussion Paper 121, Urban Paper 4, 1978).

6. S. Gera and P. Kuhn, Occupation and job location patterns: An analysis of the Toronto Census Metropolitan Area, The Canadian Geographer 23, 266-276 (1979) .

7. W. A. Johnson, "Changing Patterns of Employment in the New York Metropolitan Area," R-571-NYC, New York City Rand Institute, New York (1971)

8. P. Kemper and R. Schmenner, The density gradient for manufacturing industry, J. Urban Econ. 1, 410-427 (1974).

9. J. Kmenta, "Elements of Econometrics," Macmillan, New York (1971).

10. G. S. Maddala, "Econometrics," McGraw-Hill, New York (1977).

11. E. S. Mills, Urban density functions, Urban Studies 7, 5-20 (1970).

12. E. S. Mills, "Studies in the Structure of the Urban Economy," The Johns Hopkins Press, Baltimore (1972). 
13. E. S. Mills and K. Ohta, Urbanization and urban problems, In "Asia's New Giant" (H. Patrick and H. Rosovsky, Eds.), Brookings Institution, Washington, D.C. (1976).

14. R. I. Moomaw, An econometric analysis of industrial land-use intensity within an urban area, Urban Studies $15,321-326$ (1978) 